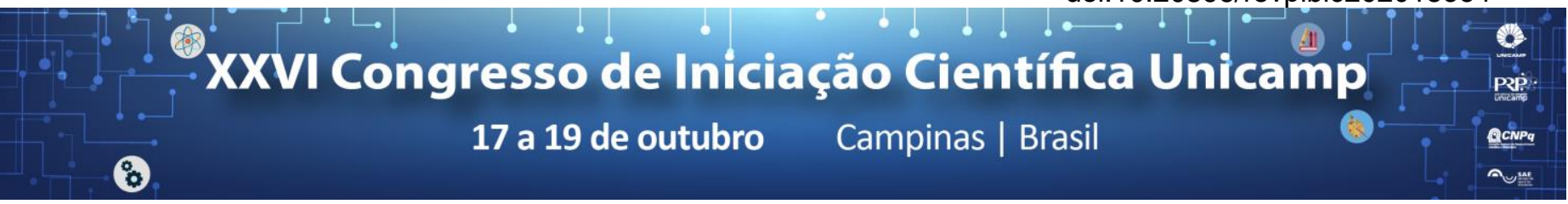

\title{
Influence of a strong polyelectrolyte on a system formed by silk fibroin and sodium alginate
}

\section{Daniela D. Quintana*, Laise M. Lopes, Marisa M. Beppu.}

\begin{abstract}
Natural polymers could be used for many applications, from food packaging to tissue engineering. The blends of silk fibroin (SF) and sodium alginate (SA) are used as biomaterials and it is known that the system formed by those polymers are partially miscible. However, there are not many studies in the literature about this system from the thermodynamic perspective. In this study, it was prepared blends with different proportions of SF, SA, water and polystyrene sulfonate (SPS) to evaluate how the polyelectrolyte influence in the SA-SF interaction. The morphology and polymer interaction were analyzed. Results show that there is an influence of the polyelectrolyte in the system formed by the natural polymers when comparing the data with blends without the presence of the SPS.
\end{abstract}

\section{Key words:}

phase separation, polymers blends, natural polymers.

\section{Introduction}

The study of natural polymers, such as SF and SA has increased due to characteristics like biodegradability, low toxicity, and biocompatibility. The blends of these polymers can be used as wound dressings and drug delivers devices ${ }^{1}$. There are some parameters that could influence in the morphological and structural characteristics of these blends, such as $\mathrm{pH}$ and temperature ${ }^{2}$. In this study, we investigated the influence of a strong polyelectrolyte in the morphology and polymer interaction. X-ray diffraction (XRD), Fourier transform infrared spectroscopy with attenuated total reflection (FTIR-ATR) and scanning electron microscopy (SEM) was performed in 7 blends with different proportion of SF, SA, water, and SPS (Figure 1).

\section{Results and Discussion}

To prepare the blends, it was used solutions of SF, SA and SPS. The solution of SF and SPS were mixture 24 hours before the blend preparation, then, it was slowly added to the SA solution. The blends membranes were casted at $25^{\circ} \mathrm{C}$. Besides that, blends in solution were prepared with the same proportion and putted in a thermostatic bath at $25^{\circ} \mathrm{C}$ to see how the system would behave. Some blends formed hydrogels (Figure 1) and the others formed two separated phases, showing that phase separation and thermodynamic equilibrium were influenced by SPS. Since results for different blends were similar in the analyses, the data shown are from the blend $\mathrm{SF}_{0,5} / \mathrm{SA}_{0,5} /$ WASPS $_{99}$. SEM results are shown in Figure 2. It is possible to see the presence of globular structures and SF fibrils in the blend membranes. The fibrils are not noticed in membranes without SPS. There are evidences that the polyelectrolyte used favored the formation of SF fibril $^{2}$. XDR diffractograms patterns (Figure $3(A)$ ) and FTIR-ATR spectra (Figure 3 (B)) showed that membranes with SPS presented differences in SF secondary conformation comparing with membranes without SPS ${ }^{3}$. On the blend with the polyelectrolyte, the $\beta$ sheet conformation is present, while on the blends without SPS, the a-helix conformation is observed.

\section{Conclusions}

The results have shown that a strong polyelectrolyte (SPS) could change the morphology and SF secondary structure of the polymers blends studied.

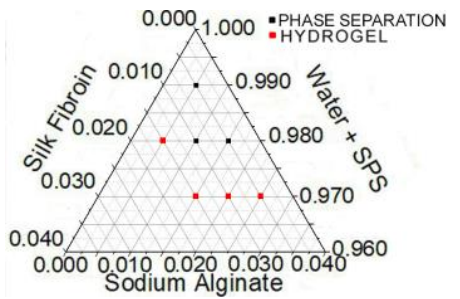

Figure 1. Ternary diagram showing the mass fractions of SF, SA, SPS and water of each blend.

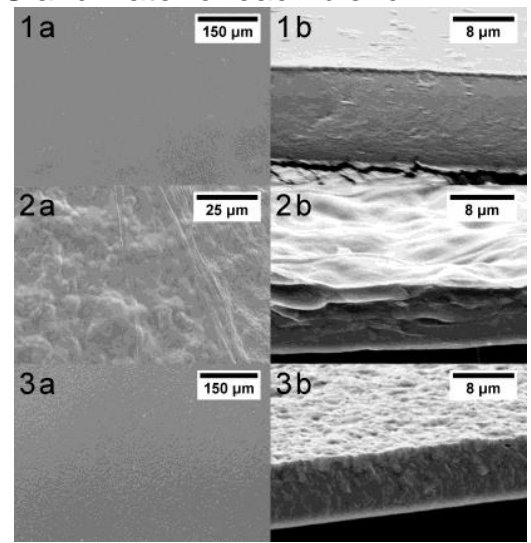

Figure 2. SEM images of surface (a) and fracture (b) of SA (1), $\mathrm{SF}_{0,5} / \mathrm{SA}_{0,5} /$ WASPS $_{99}$ blend (2) and SF membrane (3).

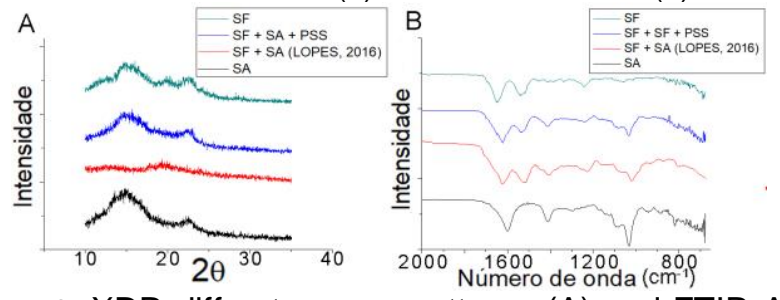

Figure 3. XDR diffractograms patterns $(A)$ and FTIR-ATR spectra (B).

\section{Acknowledgement}

I would like to thank the Conselho Nacional de Desenvolvimento Científico e Tecnológico (Pibic/CNPq).

${ }^{1} \mathrm{KOH}$, Leng-duei et al, Structures, mechanical properties and applications of silk fibroin materials, Progress in Polymer Science, v. 46, p. 86-110, 2015. 2 DE MORAES, M. A. Obtenção e caracterização de materiais micro e nanoestruturados contendo fibroína de seda combinada a outro polímero biocompatíveis para contato com célula. Tese de doutorado em Engenharia Química. Universidade Estadual de Campinas, 2014.

${ }^{3}$ LOPES, L.M. Estudo termodinâmico de blendas de fibroína de seda e alginato de sódio.Dissertação de mestrado em Engenharia Química. Universidade Estadual de Campinas, 2016. 